\title{
Fundic Gland Polyp
}

National Cancer Institute

\section{Source}

National Cancer Institute. Fundic Gland Polyp. NCI Thesaurus. Code C8961.

The most common gastric polyp in the Western hemisphere. The lesion consists of a localized hyperplasia of the deep epithelial compartment of the oxyntic mucosa, with variable degrees of cystic dilatation. Malignant transformation is the exception. (WHO, 2000) 